\title{
Keeping children safe: rethinking how we design our surroundings
}

\section{Andrew W. Howard MD MSc}

Previously published at www.cmaj.ca

$\mathrm{O}$ nly recently has the concept of designing the environment to promote public safety and health been put into practice. We have known for decades that injury is the leading cause of death among children over one year of age in industrialized countries. ${ }^{1}$ Rather than trying to retrofit environments to mitigate unsafe conditions, urban planners have begun taking into consideration the requirements for well-being across the human lifespan and designing built surroundings that meet those needs. Given the high incidence of childhood injuries, it is crucial that this new proactive style of planning aim to minimize physical risk to children. At the same time, it should maximize opportunities for physical activity.

In 2002, 371000 boys and 289000 girls died of injury worldwide. ${ }^{2}$ Over 180000 of these children were killed by roadway traffic, most as pedestrians. Drowning, fires and falls accounted for the greater proportion of the remaining deaths. Most of these children died while failing to negotiate an entirely manmade environment.

Risk of injury is related to levels of physical activity and health. Although the rate of injury by roadway traffic has been falling, the decrease is mainly because children walk much less than they used to. ${ }^{3,4}$ A sedentary childhood, adolescence and adulthood contribute to most of the chronic diseases that make up the leading causes of morbidity and mortality beyond middle age. If people lived more vigorously in past times, it was not because they were intrinsically different. Rather, the environment in which they lived either promoted sustained physical activity or required it. That quality has been unintentionally engineered out of the Western lifestyle for the sake of comfort and convenience.

Perhaps it would be more comfortable and convenient, however, not to face long commutes, unwalkable neighbourhoods and limited opportunities for physical activity in our everyday lives. The characteristics of the built environment we share have had a pervasively negative impact on the health of people of all ages. ${ }^{5-7}$ Improving the safety of our built environment is important not only because injury is the leading cause of death among children, but also because an unsafe environment is a major barrier to the levels of physical activity required for lifelong health.

\section{Key points}

- Injury is the leading cause of death among children in the industrialized world, and often involves failure to negotiate a built environment.

- Safety should be considered when designing the built environment to substantially reduce injuries and fatalities.

- Perceived lack of safety is a major barrier to the use of active modes of transportation such as walking or cycling.

- A safer environment can lead to improved public health, physical activity levels and quality of life, and reduced pollution.

\section{A shift in approach}

Prevention of injury has traditionally been based on a theoretic framework known as the Haddon matrix (Table 1). ${ }^{8}$ Using this approach, an event resulting in injury is broken down into contributing factors and phases, which are then considered separately. Countermeasures are conceived, tested and implemented for each of 3 domains, which are classified as the host (i.e., the injured person), the agent (i.e., the source of mechanical energy) and the environment, and across 3 time periods, which are pre-event, the event and post-event. This approach has been very successful in certain categories of injury, most notably the improvement of protection for occupants of motor vehicles in collisions.

Under a more recent approach used in the field of public health, the rates of mortality and disability for different diseases and injuries are assessed along with the risk factors that contribute to them. ${ }^{9}$ The Global Burden of Disease study ${ }^{9}$ reported by the World Health Organization is the best example of this method. The study identified all of the healthrelated effects of known risk factors for disease (e.g., the respiratory, circulatory and cancer-related effects of tobacco

Andrew Howard is associate professor of the Department of Surgery and the Department of Health Policy, Management and Evaluation, University of Toronto, and a pediatric orthopedic surgeon with the Hospital for Sick Children, Toronto, Ont. He is chair of the National Expert Advisory Committee for Safe Kids Canada, the national injury prevention program of the Hospital for Sick Children.

CMAJ 2009. DOI:10.1503/cmaj.080162 
Table 1: The Haddon matrix, which has been the predominant conceptual framework for prevention of injury since the 1960s. Its reductionist and analytical approach holds that small reductions in risk or severity of injury at 3 different times and across 3 different domains can work synergistically to achieve substantial overall reductions. An analysis of injury of a child pedestrian is used here as an example.

\begin{tabular}{llll}
\hline Time period & Host (child pedestrian) & Agent (motor vehicle, driver) & Environment (road) \\
\hline Pre-event & $\begin{array}{l}\text { Education in pedestrian } \\
\text { safety }\end{array}$ & $\begin{array}{l}\text { Driver training } \\
\text { Impaired driving laws }\end{array}$ & $\begin{array}{l}\text { Crossing controls } \\
\text { Speed humps } \\
\text { Traffic-calming measures } \\
\end{array}$ \\
& Supervision & Speed control & Physical barriers \\
Event & $\begin{array}{l}\text { Pedestrian-friendly vehicular } \\
\text { design }\end{array}$ & \\
& Access to trauma care & & Emergency medical service \\
Post-event & Access to rehabilitation & & System for care of trauma victims \\
\hline
\end{tabular}

smoking) and compared these to the health-related effects of other common risk factors (e.g., hypertension).

This "common risk factors" approach represents a newer way of thinking about complex health-related issues such as injury. The built environment is a common risk factor that affects many health-related outcomes, including risk of injury, levels of activity, lifelong cardiovascular health, levels of pollution and many aspects of quality of life. These domains should therefore be considered and studied together where possible.

When assessing the effects on health of the built environment, an approach based on common risk factors is attractive for 2 reasons (Figure 1). First, we have only one built environment for all ages and all types of injury, so modifications to that environment should be evaluated more broadly than against a single type of injury in a single age group. Second, making changes to the built environment may have multiple and opposite effects on public health and other domains. For example, walking more may be good for one's cardiovascular health, but it may also be bad for one's risk of injury. As such, it may be either good or bad for the overall quality of life of the general population. An analysis of the potential effects of making changes to the built environment, therefore, should take into account all demographic groups of the population and other important outcomes.

\section{International comparisons}

Wide variations exist internationally both in the level of attention given by individual countries to the built environment and in socio-economic gradient (i.e., the relation between socio-economic status and incidence of disease and injury). As a result, large contrasts exist even among affluent nations in childhood mortality due to injury. The striking degree of such contrasts is shown in Table 2 .

Injury accounts for about $40 \%$ of all childhood deaths in the industrialized world today. Rates of injury-related death have declined in affluent countries since the 1970s. Yet they have done so at a much slower rate than deaths from other causes. About 15000 childhood deaths per year could be avoided in affluent countries if all of them attained the low rate of death reported for Sweden. For each injury-related death prevented, 160 admissions to hospital and 2000 visits to emergency departments could be prevented. ${ }^{1}$

Affluent countries have an overall rate of death from injury among children aged 14 and younger of 15.3 per 100000 for boys and 10 per 100000 for girls. By contrast, in higher-mortality, developing countries, the rates are 50.5 per 100000 for boys and 43.5 per 100000 for girls. ${ }^{2}$ With their much higher populations and younger demography, developing countries bear most of the global burden of childhood injury. A billion people live in urban slums - a built environment that exposes children to the highest rates of injury and violence. A billion more people will live in urban slums by 2020, accounting for half of the growth of the global population between now and then..$^{10}$ If affluent countries are to address the burden of illness worldwide, efforts in international development must include working toward improving the built environment in these very constrained settings to improve human health and potential.

\section{Socio-economic status and safety}

In Canada, as in all countries, a strong correlation exists between socio-economic status and the risk of injury-related death among children. ${ }^{11-14}$ Children in low socio-economic levels are more than twice as likely to die of injury than children in high levels. ${ }^{15}$ This difference is particularly striking for deaths that are due to fires, drowning, falls and pedestrian injuries all of which are strongly influenced by the built environment.

Socio-economic gradients in the risk of injury could be due to environmental factors, knowledge- and behaviourrelated factors, or both. Where childhood injury is concerned, the differences in the environment seem to be more important for traffic injuries ${ }^{14,16}$ and for falls or other injuries in the home setting. ${ }^{17,18}$ Lower use of bicycle helmets seen in areas of lower socio-economic status ${ }^{19}$ suggests that behavioural differences exist across different socio-economic levels and may play a role in some types of injuries. Certain programs (e.g., walking bus programs that allow children to walk to and from 


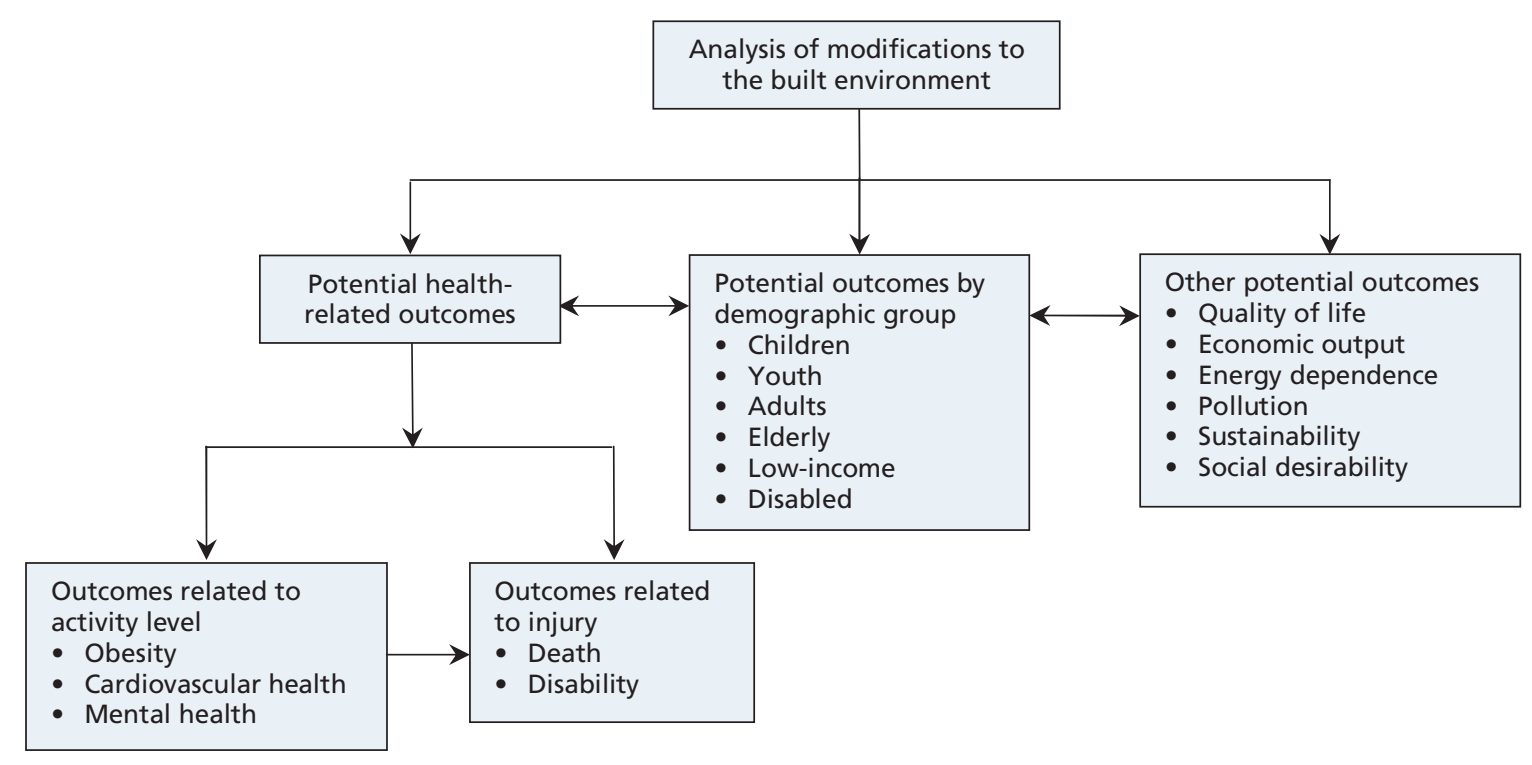

Figure 1: The "common risk factors" approach.

school in chaperoned groups ${ }^{20}$ may be more sustainable in affluent areas. Any attempt to modify the built environment to reduce injury, therefore, must take into consideration the question of whether targeting economically deprived areas is likely to increase the effectiveness of the intervention. In many cases, the answer is likely to be yes.

\section{Traffic}

Child pedestrians are vulnerable users of the road - unprotected from the kinetic energy of speeding automobiles and incapable of making mature judgements to minimize their risk of harm from traffic. Fortunately, there is substantial evidence that modifying the built environment can increase the safety of child pedestrians.

What is more, safer walking generally means more walking. An added benefit of making traffic safer for children is that it increases the likelihood that children will walk. Among Canadian children, 50\% never walk to school compared with $17 \%$ who do so most of the time. Three quarters have never ridden a bicycle to school. Parents report that traffic-related dangers and distance are the principal reasons that their children do not walk or cycle to school. ${ }^{21}$ Similar reports from parents in the United States ${ }^{22}$ and Australia ${ }^{23}$ suggest that taking action to make pedestrian commutes to school safer and shorter may be an important intervention for public health. (Children themselves reported that they disliked walking to school uphill - a much more difficult environmental factor to modify!)

Trends over the past 50 years in the United States show a decline in physical activity during transport, work, housework and overall. Eighty-six percent of utilitarian trips are now made by automobile and $8.6 \%$ by walking. ${ }^{24}$ Because nearly all children are pedestrians and none are drivers, a child's journey to school is the natural place to start reversing these overwhelming trends away from active transportation. Encouraging children to walk to school means ensuring that when communities are built, they are designed appropriately to allow short, safe walks from home to school and other destinations. ${ }^{25}$

Two systematic reviews have supported the use of modifications to the environment to reduce pedestrian injuries. ${ }^{26,27}$ The first reviewed literature on traffic engineering and defined 3 types of interventions involving changes to the built environment. These interventions were speed control, separation in time (e.g., exclusive traffic-light phasing) or in space (e.g., fencing), and the enhancement of pedestrian visibility. The best-quality evidence came from before-after studies using control groups (equivalent to level 3 clinical evidence), although some studies had weaker designs. The review concluded that pedestrian injuries can be reduced by $50 \%-75 \%$ in specific locations and $25 \%$ area-wide by implementing environmental interventions alone or in combination. ${ }^{26}$

The second review assessed methodologic quality and included 16 controlled before-after studies. It reported evidence for a $37 \%$ reduction in fatal outcomes and an $11 \%$ reduction in severe outcomes using area-wide traffic calming. ${ }^{27}$ Both of these reviews considered adult and child pedestrians together, and both were limited by their basis on controlled before-after studies at best, with no randomized trials. A case-control study that was specific to children drew attention to traffic volume, curb parking and speed over $40 \mathrm{~km} / \mathrm{h}$ as important environmental risk factors for injury among child pedestrians. ${ }^{28} \mathrm{~A}$ similar study estimated that speed humps reduced the risk of injury to child pedestrians by $53 \%$ in California. ${ }^{29}$

Because local traffic environments differ in their specific characteristics, no overall solution exists for preventing injury 
Table 2: Rates of death from injury, shown overall and by type of injury, among children aged 1-14 in selected countries (for which cause-specific data were available). Data are from the 2001 Unicef Innocenti Report on Child Injury Deaths in Rich Countries ${ }^{6}$ and include deaths occurring between 1991 and 1995.

\begin{tabular}{lcccccrr}
\hline Country & $\begin{array}{c}\text { Deaths of children from } \\
\text { injury (per 100 000/yr) }\end{array}$ & Transport & Drowning & Fire & Falls & $\begin{array}{c}\text { Deaths of children } \\
\text { from injury (per yr) }\end{array}$ & $\begin{array}{c}\text { Lives saved (per yr) if all } \\
\text { countries matched } \\
\text { lowest rates }\end{array}$ \\
\hline Sweden & 5.20 & - & - & - & - & - & 78 \\
UK & 6.06 & 2.91 & 0.39 & 0.66 & 0.26 & 637 & 51 \\
Canada & 9.68 & 4.33 & 1.26 & 1.01 & 0.20 & 533 & 747 \\
USA & 14.06 & 5.76 & 1.74 & 1.65 & 0.23 & 7453 & 2525 \\
Korea & 25.57 & 12.59 & 5.10 & 0.91 & 1.18 & 2500 \\
\hline
\end{tabular}

among child pedestrians. However, we have consistent empiric evidence that modifying the built environment reduces pedestrian injury. By contrast, merely educating children on proper ways to cross the road has been shown in a systematic review to change only the behaviour of children but not rates of injury. ${ }^{30}$ Randomized trials of educational interventions showed that children who were given such training were 1.6 to 2.2 times more likely to exhibit safe behaviour (i.e., stopping, looking) while crossing the street. No randomized trial involving pedestrian education has reported injury-specific outcomes, however, and no such trial has been done in the setting of a developing country, where the burden, risk and rate of increase of pedestrian deaths among children are much greater. ${ }^{30}$

Most parents would be more likely to let their children walk if other children were walking. ${ }^{31}$ This finding is consistent with empiric evidence that cyclists and pedestrians are safer if present in greater numbers. ${ }^{31} \mathrm{~A}$ "safe routes to school" program in California documented an increase in walking among schoolchildren after implementation of the program. ${ }^{32}$ Area-wide traffic-calming initiatives in the United Kingdom were shown to lead to a reduction in absolute risk of injury to child pedestrians. ${ }^{33}$ This reduction was nearly $50 \%$ in economically deprived areas of the city, where these initiatives were shown to decrease the socio-economic gradient in risk of injury when traffic-calming measures were concentrated there. ${ }^{33}$ Traffic-calming measures in Glasgow resulted in an increase in physical activity and measurable improvements in physical health because of increased walking or playing outside. ${ }^{34}$

\section{Falls}

Few fatalities occur from injuries in school playgrounds, but this setting is the source of a substantial burden of morbidity from falls. Falls from climbing equipment are 5 times more likely to result in severe fractures (i.e., requiring manipulative or operative reduction) than falls from a standing height during play. ${ }^{35}$ The main risk factors for playground-related injury are falls from heights over $1.50 \mathrm{~m}$ and inadequate falling surfaces. ${ }^{36,37}$ Canadian standards for playground equipment are aimed at limiting potential falling heights and ensuring adequate energy-absorbing surfacing is provided beneath play structures. Evidence from a pre-post study using a control group (equivalent to level 3 evidence) showed that playgrounds that did not comply with standards set by the Canadian Standards Association had about twice the rate of injury of playgrounds that were in compliance. Furthermore, the removal of play equipment that did not comply with the standards and its replacement with equipment that was in compliance prevented $50 \%$ of expected injuries. ${ }^{38}$ At present, the standards set by the Canadian Standards Association are voluntary and lack regulatory authority for most public playgrounds in Canada.

Playgrounds offer developmentally appropriate physical recreation for children in a controlled environment. This environment can be designed to maximize enjoyment and activity while minimizing danger. Providing safe spaces to play increases physical activity among children living in deprived neighbourhoods. ${ }^{39}$

Schools represent a built environment that can be purposefully modified to minimize injury and maximize activity. Observational studies show that opportunities for physical play in the built environment of schools are the most important determinant of the level of physical activity undertaken by both boys and girls. ${ }^{40}$ Such studies also show that safe playgrounds (i.e., as defined by physical audit) are possible in areas of low and very low socio-economic levels. ${ }^{41}$ In Japan, having more areas for play that are safe led to fewer pedestrian deaths from 1970 to $1985 .{ }^{42}$

Falls from windows are a risk specific to toddlers. Children with a median age of 2 years have an incidence of up to 15 falls resulting in hospitalization per 100000 per year. Programs to promote safety have often targeted highrise buildings, where laws requiring window-guards have resulted in a documented and sustained decrease in fatalities. ${ }^{17}$ Whereas the majority of fatal injuries from falls occur in the setting of highrise buildings, $98 \%$ of hospital admissions for falls from windows involve toddlers in 2- and 3storey buildings. ${ }^{43}$

Both playground-related falls and falls from buildings, which together account for much of the morbidity and mortality of childhood injury, are amenable to countermeasures in the built environment. By enhancing physical activity, playground modifications in particular can promote childhood health in addition to preventing injury. 


\section{Drowning}

The incidence of drowning peaks dramatically among children aged 4 and under. The majority of these drownings occur in the home (involving infants) or in swimming pools (involving toddlers). Another peak in incidence occurs among adolescent boys and involves natural (as opposed to manmade) bodies of water. ${ }^{44}$ Given that far fewer drownings occur in public pools with lifeguards than in domestic swimming pools, modifications aimed at promoting public infrastructure may also reduce the risk of drowning among children. ${ }^{44}$

Childhood drownings in domestic swimming pools are increasing in Canada along with the popularity of inexpensive, above-ground pools. A systematic review of case-control studies concluded that pool fencing would prevent $73 \%$ of childhood drownings in an unfenced pool. Complete enclosure of the pool on all sides by a fence would prevent an additional $83 \%$ of drownings compared with incomplete fencing (i.e., with a house opening into the pool enclosure) ${ }^{45}$ Limitations of this review include the fact that the data are drawn from case-control rather than randomized designs. With rare exceptions, however, such studies likely represent the best information available. Studies using a case-control design may overestimate the benefit of having a fenced pool if the fence is a marker for other safety-related behaviours that are not measured and that cannot be legislated. Modifications to building codes and municipal bylaws across Canada to mandate all-sided fencing around swimming pools could potentially save the lives of many children who drown in Canada each year.

\section{Conclusion}

In 1900 , only $13 \%$ of the global population lived in cities. In 2005, 80\% of Canadians lived in cities. ${ }^{46}$ Big cities are a recent innovation not yet perfected. By giving priority to automotive over pedestrian transportation, we have allowed road traffic to become the leading cause of death among our children. North American children are increasingly sedentary. Cross-sectional analyses of national data for the United States show that urban sprawl is associated with higher rates of both traffic-related injury ${ }^{47}$ and obesity ${ }^{48}$ among adolescents.

Modifying our built surroundings makes walking safer and encourages children to walk more. It prevents childhood deaths from falls and drowning and reduces injuries. It allows children more physical play that is also safer.

As we move from a reductionist approach in the prevention of childhood injury (i.e., 1 risk factor at a time) to an approach that addresses common risk factors and considers underlying causes (i.e., the built environment, poverty), we uncover important gaps in our knowledge. We need direct research that will establish the extent of the association between our built environment and both positive and negative health-related outcomes.

Our built environment influences our children's levels of activity, their physical health and their risk for injury. It influences levels of pollution and our very quality of life. The dual benefits of reducing injury and increasing physical activity by modifying the built environment must be considered and studied together to ensure both are achieved. Intelligent planning, particularly with consideration for urban design and traffic engineering to emphasize safe walking and cycling, has enormous potential to improve the health and safety of children now and across the lifespan.

Safe Kids Canada (www.safekidscanada.ca) has prepared a legislation advocacy kit to make it simple for health care practitioners or others to implement appropriate changes in their own communities. Following the Safe Kids campaign, several municipalities have already passed bylaws based on this draft legislation. Any concerned practitioner can bring this package to the attention of local municipal authorities to effect change in his or her community. ${ }^{49}$

This article has been peer reviewed.

Competing interests: None declared.

\section{REFERENCES}

1. UNICEF Innocenti Research Centre. Innocenti report card issue no. 2 February 2001: A league table of child deaths by injury in rich nations. Florence (Italy): United Nations Children's Fund; 2001, p. 12. Available: www.unicef-irc.org /publications/pdf/repcard2e.pdf (accessed 2009 Feb. 25).

2. World Health Organization. Global burden of disease: 2004 update. Geneva(Switzerland): The Organization; 2009 Available: www.who.int/healthinfo /global_burden_disease/en/index.html (accessed 2009 Feb. 25).

3. Roberts I. Safely to school? Lancet 1996;347:1642.

4. Roberts I. Why have child pedestrian death rates fallen? BMJ 1993;306:1737-9.

5. Srinivasan S, O'Fallon LR, Dearry A. Creating healthy communities, healthy homes, healthy people: initiating a research agenda on the built environment and public health. Am J Public Health 2003;93:1446-50.

6. Jackson RJ. The impact of the built environment on health: an emerging field. Am J Public Health 2003;93:1382-4.

7. Lavizzo-Mourey R, McGinnis JM. Making the case for active living communities. Am J Public Health 2003;93:1386-8.

8. Runyan CW. Using the Haddon matrix: introducing the third dimension. BMJ 1998;4:302-7.

9. Murray CJ, Lopez AD. Global mortality, disability, and the contribution of risk factors: Global Burden of Disease Study. Lancet 1997;349:1436-42.

10. Sclar ED, Northridge ME. Slums, slum dwellers, and health. Am J Public Health 2003;93:1381.

11. Reimers A, Laflamme L. Neighbourhood social and socio-economic composition and injury risks. Acta Paediatr 2005 Oct;94(10):1488-94.

12. Moustaki M, Petridou E, Trichopoulos D. Person, time and place coordinates of pedestrian injuries: a study in Athens. Acta Paediatr 2001 May;90(5):558-62.

13. Laflamme L, Diderichsen F. Social differences in traffic injury risks in childhood and youth - a literature review and a research agenda. Inj Prev 2000 Dec;6(4):293-8.

14. Birken CS, Parkin PC, To T, et al. Trends in rates of death from unintentional injury among Canadian children in urban areas: influence of socioeconomic status. [see comment]. CMAJ 2006;175:867.

15. Macpherson A, Roberts I, Pless IB. Children's exposure to traffic and pedestrian injuries. [see comment]. Am J Public Health 1998;88:1840-3.

16. Rivara FP, Barber M. Demographic analysis of childhood pedestrian injuries. Pediatrics 1985;76:375-81.

17. Committee on Injury and Poison P. American Academy of Pediatrics. Falls from heights: windows, roofs, and balconies. Pediatrics 2001;107:1188-91.

18. Gielen AC, Wilson ME, Faden RR, et al. In-home injury prevention practices for infants and toddlers: the role of parental beliefs, barriers, and housing quality. Health Educ Q 1995;22:85-95.

19. Parkin PC, Khambalia A, Kmet L, et al. Influence of socioeconomic status on the effectiveness of bicycle helmet legislation for children: a prospective observational study. Pediatrics 2003;112:e192-6.

20. Collins DCA, Kearns RA. Geographies of inequality: child pedestrian injury and walking school buses in Auckland, New Zealand. Soc Sci Med 2005;60:61-9.

21. Public Health Agency of Canada. Go for green: 2004 National survey on active transportation. Toronto (ON): Institute for Social Research, York University; 2006.

22. Centers for Disease Control and Prevention (CDC). Barriers to children walking to or from school - United States, 2004. MMWR Morb Mortal Wkly Rep 2005;54:949-52. 


\section{HYDROMORPH Contingi2h}

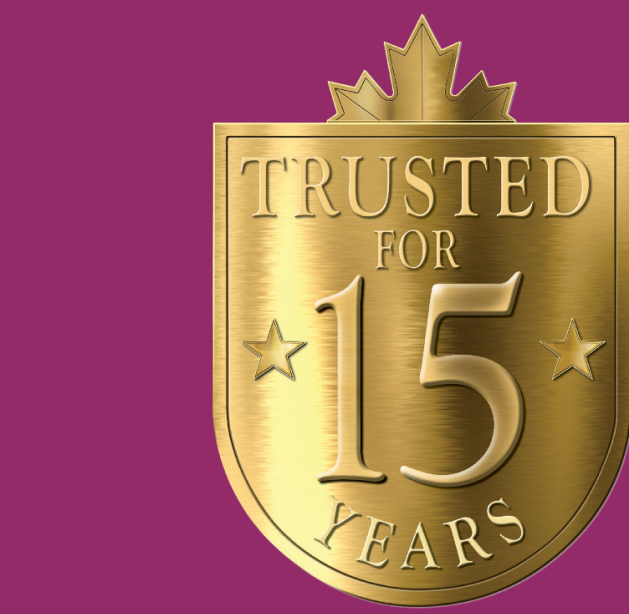

STRENGTH YOU CAN COUNT ON. EXPERIENCE YOU CAN RELY ON.

Hydromorph Contin ${ }^{\circledR}$ is indicated for the relief of severe chronic pain requiring the prolonged use of an oral opioid preparation.

Side effects are similar to other opioid analgesics. The most frequently observed are asthenic conditions, confusion, constipation, dizziness, lightheadedness, nausea, sedation, sweating and vomiting. Dosage limitations may be imposed by adverse effect. If they occur, please refer to prescribing information. Warning: Opioid analgesics should be prescribed and handled with a high degree of caution appropriate to the use of a drug with strong abuse potential. Patients should be cautioned not to consume alcohol while taking Hydromorph Contin ${ }^{\circledR}$, as it may increase the chance of experiencing dangerous side effects. Hydromorph Contin ${ }^{\circledR} 18 \mathrm{mg}$ capsules and higher are for use in opioid tolerant patients only. There is a potential for fatal respiratory depression in patients not previously exposed to similar equianalgesic doses of an opioid analgesic. Hydromorph Contin ${ }^{\circledR}$ capsules or capsule beads should not be chewed, crushed or dissolved since this can lead to rapid release and absorption of a potentially fatal dose of hydromorphone. Product monograph available on request. Hydromorph Contin ${ }^{\circledast}$ capsule beads may be sprinkled on cold, soft food.

\section{REVIEW}

23. Timperio A, Ball K, Salmon J, et al. Personal, family, social, and environmenta correlates of active commuting to school. Am J Prev Med 2006;30:45-51.

24. Brownson RC, Boehmer TK, Luke DA. Declining rates of physical activity in the United States: What are the contributors? Annu Rev Public Health 2005;26:421-43.

25. Kerr J, Rosenberg D, Sallis JF, et al. Active commuting to school: Associations with environment and parental concerns. Med Sci Sports Exerc 2006;38:787-94.

26. Retting RA, Ferguson SA, McCartt AT. A review of evidence-based traffic engineering measures designed to reduce pedestrian-motor vehicle crashes. Am J Public Health 2003;93:1456-63.

27. Bunn F, Collier T, Frost C, et al. Area-wide traffic calming for preventing traffic related injuries [review]. Cochrane Database Syst Rev 2003;(1):CD003110.

28. Roberts I, Norton R, Jackson R, et al. Effect of environmental factors on risk of injury of child pedestrians by motor vehicles: a case-control study. $B M J$ 1995;310:91-4.

29. Tester JM, Rutherford GW, Wald Z, et al. A matched case-control study evaluating the effectiveness of speed humps in reducing child pedestrian injuries. Am J Public Health 2004;94:646-50.

30. Duperrex O, Bunn F, Roberts I. Safety education of pedestrians for injury prevention: a systematic review of randomised controlled trials. BMJ 2002;324:1129.

31. Jacobsen PL. Safety in numbers: more walkers and bicyclists, safer walking and bicycling. Inj Prev 2003;9:205-9.

32. Boarnet MG, Anderson CL, Day K, et al. Evaluation of the California Safe Routes to School legislation: urban form changes and children's active transportation to school. Am J Prev Med 2005;28(Suppl 2):134-40.

33. Jones SJ, Lyons RA, John A, et al. Traffic calming policy can reduce inequalities in child pedestrian injuries: database study. Inj Prev 2005;11:152-6.

34. Morrison DS, Thomson H, Petticrew M. Evaluation of the health effects of a neighbourhood traffic calming scheme. J Epidemiol Community Health 2004;58:837-40.

35. Fiissel D, Pattison G, Howard A. Severity of playground fractures: play equipment versus standing height falls. Inj Prev 2005;11:337-9.

36. Macarthur $\mathrm{C}, \mathrm{Hu} \mathrm{X}$, Wesson $\mathrm{DE}$, et al. Risk factors for severe injuries associated with falls from playground equipment. Accid Anal Prev 2000;32:377-82.

37. Mowat DL, Wang F, Pickett W, et al. A case-control study of risk factors for playground injuries among children in Kingston and area. Inj Prev 1998;4:39-43.

38. Howard AW, MacArthur C, Willan A, et al. The effect of safer play equipment on playground injury rates among school children. CMAJ 2005;172:1443-6.

39. Farley TA, Meriwether RA, Baker ET, et al. Safe play spaces to promote physical activity in inner-city children: results from a pilot study of an environmental intervention. Am J Public Health 2007;97:1625-31.

40. Sallis JF, Conway TL, Prochaska JJ, et al. The association of school environments with youth physical activity. Am J Public Health 2001;91:618-20.

41. Powell EC, Ambardekar EJ, Sheehan KM. Poor neighborhoods: safe playgrounds J Urban Health 2005;82:403-10.

42. Nakahara S, Nakamura Y, Ichikawa M, et al. Relation between increased numbers of safe playing areas and decreased vehicle related child mortality rates in Japan from 1970 to 1985: a trend analysis. J Epidemiol Community Health 2004;58:976-81.

43. Vish NL, Powell EC, Wiltsek D, et al. Pediatric window falls: not just a problem for children in high rises. Inj Prev 2005;11:300-3.

44. Brenner RA. Prevention of drowning in infants, children, and adolescents. Pediatrics 2003;112:440-5

45. Thompson DC, Rivara FP. Pool fencing for preventing drowning in children [review]. Cochrane Database Syst Rev 2000;(2):CD001047.

46. United Nations. World urbanization prospects: the 2005 revision. New York (NY): Department of Economic and Social Affairs, Population Division; 2005. Available: www.un.org/esa/population/publications/WUP2005/2005wup.htm (accessed 2008 Jan. 10)

47. Ewing R, Schieber RA, Zegeer CV. Urban sprawl as a risk factor in motor vehicle occupant and pedestrian fatalities. Am J Public Health 2003;93:1541-5.

48. Ewing R, Brownson RC, Berrigan D. Relationship between urban sprawl and weight of United States youth. Am J Prev Med 2006;31:464-74.

49. Safe Kids Canada. Public policy and advocacy - Safer pool fencing laws. Toronto (ON): Safe Kids Canada; 2007. Available: www.safekidscanada.com /SKCPublicPolicyAdvocacy/section.asp?s=Safer\%2BPool\%2BFencing\%2BLaws $\&$ sID=20563 (accessed 2009 Sept. 23)

Correspondence to: Dr. Andrew Howard, Department of Orthopedics, Rm. S-107, The Hospital for Sick Children, 555 University Ave., Toronto ON M5G 1X8; andrew.howard@sickkids.ca 